\title{
Socially Aware Design of Games: an early workshop for game designers
}

\author{
Bernardo Ferrari (1) [ Universidade Federal do Paraná $\mid$ bferrari@inf.ufpr.br ] \\ Deógenes P. da Silva Junior (1) [ Universidade Federal do Paraná | dpsjunior@inf.ufpr.br ] \\ Carolina Moreira Oliveira (1) [ Universidade Federal do Paraná | cmoliveira@inf.ufpr.br ] \\ Júlia S. B. Ortiz (D) [ Universidade Federal do Paraná|jsbortiz@inf.ufpr.br ] \\ Roberto Pereira (10) [ Universidade Federal do Paraná |rpereira@inf.ufpr.br ]
}

\begin{abstract}
Designing games to encourage players' positive and healthy behaviors is both a necessity and a challenge. When the design context is critical, such as education or health, understanding the context in which the game will be inserted before proposing and designing it is a matter of social and ethical responsibility. Although the game research field has relevant contributions regarding gamification and serious game, supporting designers to develop early knowledge and responsibility for the problem context still demands investigation and attention. This paper presents and discusses a collaborative workshop to promote both designers' responsibility and problem understanding capacity since the early stages of game design, before directly engaging other stakeholders. The workshop was conducted to produce a systemic and socially responsible understanding for a prospective game to support children in speech therapy exercises, focusing on both human and technical aspects, possible solutions and their implications. This paper presents the workshop, its main results, lessons learned, as well as artifacts and practices that may be useful to inspire designers and researchers in other contexts.
\end{abstract}

Keywords: Game Development, Speech Therapy, Socially Aware Design

\section{Introduction}

Digital games already permeate human life, not only as entertainment, but as means of education, therapy assistance, among others. Games are artifacts that impact on social reality, as gaming is a social activity and a major component of teens' overall social experience (Lenhart et al., 2008). For serious games, which the purpose goes beyond entertainment, such as education, safety or health, the design process is challenging, covering different objectives and challenges for the involved ones, who can either directly interact or not with the game.

Designing a game for broader purposes must be careful, socially aware and responsible. Before starting the development of any solution and before involving interested parties and stakeholders, designers must create a broad, critical and responsible shared understanding about the problem to be addressed, the context in which the game will be available, the expected impact with its adoption, the possible consequences it may trigger, and the context that gives meaning to it. This shared understanding favors to meet the needs of the different stakeholders involved and prevents from triggering harmful effects on people that will be somewhat affected or involved in game design and usage.

However, the literature in games, even though it has attracted a lot of attention in recent years, tend to focus its research on other aspects of gameplay, as gamification and persuasive computing, letting the discussion of social and ethical responsibility of designers aside. In this paper, we present an early workshop conducted to promote a shared understanding of multiple aspects involved in the design of a serious game to support speech therapy treatments. Artifacts from (and inspired by) the Socially Aware Design approach (Baranauskas, 2009) were used to promote conversations and discussions among designers in the early stages of game design, aiming at creating a shared understanding about the problem and to raise designers' awareness about both context richness/complexity as well as their professional and social responsibility. We argue that such early discussions and conversations are mandatory for an effective and responsible design, socially aware of stakeholders' characteristics, possibilities and demands, since the very beginning of a design project $^{1}$.

Socially Aware Design, initially named Socially Aware Computing, means the "theory, artifacts and method we need to articulate to actually make design socially responsible, participatory and universal as process and product" (Baranauskas, 2009). Inspired by Organizational Semiotics (Stamper et al., 2000) and Participatory Design (Schuler and Namioka, 1993), this design model places systems understanding and technology design at the informal level (habits, values, culture), formal level (procedures, rules) and technical level (computer system) (Baranauskas, 2009) of information systems. These different levels support design from a sociotechnical perspective, considering social aspects that influence the design of the technical solution as well as the likely impacts such a solution causes when it is inserted in the social world. From our point of view, Socially Aware Design has the potential to contribute to game design as it informs and provokes reflections on the problem domain and the potential impact of the solution in the social world, including on challenging aspects such as culture and human values (Leitão et al., 2017; Pereira et al., 2018).

Socially Aware Design is mainly a perspective to the design of interactive technology. According to Piccolo and

\footnotetext{
${ }^{1}$ This paper is a revised and extended version of Ferrari et al. (2019), published in Portuguese. This new version provides new content and discussions in English, including details about the artifacts and the methodology.
} 
Pereira (2017), this perspective: i) requires the articulation of meanings of a social group at its informal and formal levels for the co-construction of the system at the technical level; ii) recognizes the other and their differences as essential elements for a systemic view; iii) recognizes communication between the parties as a culturally defined social phenomenon and proposes artifacts to mediate that communication; iv) entrusts stakeholders with the power to design and enables their creative and responsible involvement in design solutions; v) is situated in a socioeconomic and cultural reality, without losing its location in the broader world.

The situated context for our research is the "SocioEnactive systems" project (Baranauskas, 2015), which seeks to develop the concept and practice of computer systems consisting of human and technological processes dynamically linked. The project is being conducted in partnership with the SOBRAPAR Hospital for the design and experimentation of solutions that contribute to the quality of life of people who frequent the hospital environment, such as children, family and visitors. The development of computational solutions for hospital contexts must consider social issues (affective, cultural, values) of the people who are in that environment, considering aspects besides utility and easiness of use (Silva et al., 2019).

Based on an ethnographic study conducted at the hospital (Silva et al., 2019), speech therapy was identified as an opportunity for the development and application of computational solutions. The study revealed that activities are dependent on technology to work properly and effectively, and that doctor-patient interaction goes beyond the hospital environment, entering the home environment through messaging applications (apps) available on smartphones of patients and their families. Among several demands and opportunities, speech therapy professionals from the hospital raised the need for interactive computing solutions (e.g., a game) that could help patients, mostly children, to carry out exercises the professionals oriented during the medical consultation.

Speech therapy is a continuous treatment. Sessions inside the hospital are only part of the treatment, requiring also medication and exercises to be performed continuously outside the hospital. When it comes to children, there are additional difficulties to perform speech exercises at home, either due to lack of motivation, discipline or even shame, which can compromise children's evolution with treatment. Games have the potential to engage children in performing speech exercises. In order to be successful, however, the design of a game must start from this very early understanding of its different interested parties' contexts of life.

Having as starting point results from the ethnographic study and contact with speech therapy professionals at the hospital, a socially aware design workshop was conducted to foster problem understanding, designers' responsibility, and to prospect solutions that could be built and evaluated. The main purpose of a socially aware workshop is to create a shared understanding for designers and to promote their empathy for the problem before involving stakeholders (professionals, patients) and before presenting any idea or product to them.

The workshop was inspired by Baranauskas' SemioParticipatory Workshops (Baranauskas et al., 2013). Partici- pants were all from Human-Computer Interaction (HCI) field with undergraduate and graduate education degrees. They were engaged in activities to understand the problem and come up with prospective solutions, looking at the problem from the perspective of different stakeholders at the infor$\mathrm{mal}$, formal and technical levels. The workshop articulated both theoretical and methodological discussions with handson activities with the participants, favoring not only their problem-understanding skills but also their sensitivity and empathy for the problem as well as their responsibility when trying to solve it. At the end of the workshop, designers had created a shared understanding (and responsibility) for the problem using different artifacts and practices and had produced ideas and aspects for a prospective game directed to two main stakeholders: patients (children) and speech therapists. Results from the workshop and discussion with the participants reinforced our claim that a socially aware workshop is mandatory in the early stages of game design for critical contexts.

This paper is organized as follows: Section 2 presents the situated context for our research and its relation with the socially Aware Design approach; Section 3 describes the workshop and its main activities; Section 4 presents the main results from the workshop; Section 5 presents our discussions on the results, and Section 6 presents our learned lessons and directions for future research and practice.

\section{Problem Context}

Voice and speech problems can affect communication and social life, and can influence on psychological and emotional disturbs (Krischke et al., 2005). Therapy treats adults and children speech and language problems that may have been caused by different conditions, such as diseases, disabilities, injuries, among others (Frost and McCrindle, 2016).

About $10 \%$ of children aged 4-7 have some voice or speech disorder (Schipor et al., 2012). These problems vary in degree, more severe in children with craniofacial deformities. Kummer (2013) states that children with craniofacial syndromes are at greatest risk for speech and language disorders. Professional assistance is necessary to promote correct speech development or, in some cases, to return the ability to speak correctly (Frost and McCrindle, 2016). The speech therapy is one of the services offered by the SOBRAPAR Hospital.

SOBRAPAR Hospital is a philanthropic institution that offers surgical treatment and rehabilitation for patients with congenital or acquired craniofacial deformities. Patients receive free care each 2 weeks through the Brazilian Unique Health System, in which treatment is monitored. In addition to attending the hospital, speech therapy professionals require their patients to perform exercises at home, preferably seven days a week.

The Hospital has challenges regarding speech therapy such as prolonging treatment and increasing costs when exercises are not properly performed at home, reducing the expected benefits. Another challenge is access and attendance in face-to-face care, as many patients live in distant locations from the Hospital and need to travel great distances (tens or 
hundreds of kilometers) for consultation. There is some resistance from patients, mostly children, to attend consultations.

The performance of speech therapy exercises at home is important and must be effective and useful to those involved, such as speech therapists, children and their families. The Hospital demand resources to promote engagement in treatment in a way that makes sense for its (informal and formal) context and its audience, contributing to the stakeholders involved. From an ethnographic study (Silva et al., 2019), we identified digital games as a promising resource for therapists as well as to promote fun and appeal to the patients, who were mostly child's aged 7 to 11 years (Santos et al., 2019).

\subsection{Socially Aware Design and Games}

Playing is a seductive activity for children and Speech therapists can use playing to provoke children's interest, leading to new learning acquisitions (Pollonio and Freire, 2008). Care and treatment with children may follow a ludic approach, contributing to their interest and commitment with the proposed activities. One way of playing is through games, which can be used by speech therapists, parents and teachers as teaching instruments that facilitate perceptual, auditory and visual activities.

Games can have specific goals other than entertaining, as serious, educational or therapeutic games. Educational games are those designed to teach while entertaining (Novak, 2011), while serious games consider the same goals of education and entertainment, but include different aspects of education: teaching, training and information (Michael and Chen, 2005). Digital therapeutic games, in turn, are digital games that produce a direct, expected, and intended therapeutic effect on patients by playing them (Mader et al., 2016). This therapeutic effect may be to alleviate, to improve or to heal specific condition of the patients.

In the same way serious games are intended to help teachers rather than replacing them (Michael and Chen, 2005), therapeutic games are not intended to replace health professionals but to support them in their professional activities. Speech therapists can use games to play and, therefore, stimulate language with children, obtaining means to check their progress (Pollonio and Freire, 2008). Games may encourage speech therapy activities in contexts other than hospitals encouraging active learning (Novak, 2011), for example, by providing children feedback and means to learn about their own speech, and by providing therapist useful data about their patients progress.

Designing games to operate in a delicate and complex scenario such as speech therapy problems is a challenge both in terms of support for therapy and in educational aspects. Designing games to support speech therapy is not just about developing an entertainment game. Toolkits and existing approaches to leisure and entertainment games development cannot simply be transferred to education or health because of their different characteristics (Westera et al., 2008). A game to support speech therapy has also additional complexity by relating education, medical treatment and a challenging audience (i.e.., children) very often in challenging socioeconomic conditions.

From August to September 2018, a search for applications (apps) related to speech therapy was conducted on Play Store and App Store to identify existing options for the speech therapy problem, their positive aspects and opportunities. The search was carried out with the following terms: "speech therapy", "audiology", "dysphagia" and "articulation". A total of 240 results were returned - duplicate apps were not removed (duplicated between different searches and between the Play Store and App Store). Search results were ordered by relevance and the first 40 results related to speech therapy for children were selected from each search with different terms.

Among the retrieved apps, three distinct groups were identified:

- games that rely on an external person to ensure proper punctuation;

- games that present the image of an object, or pronounce words and await the identification of syllables by users;

- games moved by users-made sound.

There is a distinction between i) solutions that were designed for professionals in the field to use with their patients and ii) solutions designed specifically for children. Games designed for professionals often require registration, internet, have an interface full of text and a layout of menus or options not always easy to understand. Games designed for children are the opposite: objective punctuation, easy to learn and use, with large, colorful menus and aided by icons, sometimes even not requiring reading skills. Among the analyzed apps, the ones that most fit the scope of our research were $F_{O}$ fuu and Amigofono ${ }^{2}$, which have a high cost, around 200 to 700 reais (BRL) per year, varying the price according to the number of patients and the size of the exercise library. Only the paid app Fofuu uses voice as input for playing the game.

Fofuuu offers 10 games with dozens of levels in total, which can be applied in several different phonemes. When testing this app, problems were identified that can cause difficulties for players. For example, the speech recognizer has errors in the accuracy of speech match: in one of the games played, the game's own sound was understood as the user's voice, causing movements to be recorded involuntarily or changing the score even when the player was silent. The game interface is difficult to use with small elements and errors occur when changing the phone orientation. For different reasons varying from cost to usability and accessibility, the apps identified do not meet the demands for our context.

Several methods and frameworks have been proposed for serious or educational games. Westera et al. (2008) presents a conceptual framework for developing serious games in the genre of scenarios and narratives. The framework proposes four worlds (or subsystems) for an educational game environment: gameplay, learning, teacher, and management. Despite presenting worlds relevant to a serious game, the framework focuses on a specific type of game that mainly involves reading activity, which may not be accessible or attractive to children.

${ }^{2}$ Fofuuu is available at: https://play.google.com/store/apps/details?id= com.fofuuu.apps.therapist . Last accessed on September 6, 2020.

Amigofono is available at: https://play.google.com/store/apps/details?id= com.amigofono.app . Last accessed on September 6, 2020. 
For serious game design, Yusoff et al. (2009) presents a conceptual framework composed of educational skills and concepts as well as game elements (e.g., genres, mechanics). However, the framework only supports the development of educational and technical goals for the game. For our context, there is a previous need for establishing therapeutic objectives and the game implementation. The problem of speech therapy deals with a scenario in which it is necessary to know the hospital context, the professional practice and the underlying medical issues, as well as the different interested parties and their sociocultural contexts.

For game design from a cultural perspective, da Silva Cardoso et al. (2018) propose the E-MUnDI conceptual tool, which offers a structure for analyzing the key dimensions of User, Implementation and Diegetic Universe of a game. Although E-MUnDi has a culturally informed approach, it focuses on the design and implementation aspects of games and is not explicitly concerned in supporting designers to develop their awareness about their own responsibility when working in the social context.

For this paper, we claim early activities must be conducted to raise designers' awareness about the problem domain, the interested parties, and the cultural context of design in its widest sense, promoting professional responsibility. Therefore, we propose an early workshop for preparing the design team, creating a shared understanding and sensitivity for the design problem and project.

For our workshop, artifacts from the Socially Aware Design and Organizational Semiotics were adopted to support problem-understanding and ideas prospecting. Created by Ronald Stamper, Organizational Semiotics presents theories and methods that allow analysis and design in terms of expressing meanings, communicating intentions and creating knowledge, considering semiotic aspects of human interaction in an organization (Stamper, 2001). The Socially Aware Design (Baranauskas, 2009), in turn, offer a method that allows to produce a contextualized, responsible and systemic understanding of the problem domain, and to collaboratively generate ideas for a prospective solution before any direct contact with the target audience (e.g., children and therapists).

\section{Design Workshop}

The workshop took place in November 2018, lasting 4 hours and 20 minutes. About 10 people participated in the workshop activities: 1 graduate student in Computer Science, 4 Master students in Computer Science, 1 master's in Electrical Engineering and Industrial Informatics, $3 \mathrm{Ph}$.D. students in Computer Science, and 1 Ph.D. in HCI. Materials for the workshop: blank papers, post-its, pens and canvas banners with printed representations of artifacts (Stakeholder Identification Diagram, Evaluation Frame and Semiotic Framework).

The workshop was divided into the stages of problem understanding and ideation, both conducted in a collaborative style. The activities performed during the workshop are shown in Figure 1 mediated by the following artifacts: Stakeholder Identification Diagram, Evaluation Frame,
Value Prospecting Frame, Semiotic Framework and Brainwriting.

The workshop started with a presentation and discussion on the conceptual bases that underpin the practices that would be conducted, such as Socially Aware Design, Organizational Semiotics, and the selected artifacts. This first stage of problem-understanding lasted 1 hour and 10 minutes. Because participants had few or no experience with the artifacts and Organizational Semiotics, this first moment was relevant to establish the bases of work while providing training on the concepts that would be addressed next.

After concepts and artifacts were discussed by the participants, the SOBRAPAR Hospital and the need for supporting speech therapy for children was exposed. The presentation covered ongoing initiatives at the Hospital and the results from an ethnographic study that exposed a theme already adopted by other initiatives (story about animals, such as the "Chico monkey"), the needs of speech therapy, as well as existing solutions resulting from the search cited in the previous section (LeLe Sílabas, GameFono, Foffuu, Speech Essentials Therapy App and Speech Therapy Flashcards $\left.-S^{3}\right)$. This presentation session lasted about 30 minutes and considered: i) preliminary requirements for a computational solution arising from ethnographic studies at Hospital; ii) thematic of physical and virtual animals that inhabit the Hospital and is already adopted by other initiatives inside SOBRAPAR; iii) features of Google Play and App Store apps for supporting speech therapy practices.

Mediated by the artifacts, collaborative discussions started from identifying the different stakeholders interested and affected by the problem and its prospective solution. The Stakeholder Identification Diagram supported this practice which took about 20 minutes. The purpose of identifying stakeholders is to clarify the problem and to build a shared knowledge and awareness between the workshop participants, inciting participants to think beyond obvious types of stakeholders and raising their concern regarding the diversity of interested parties that can both influence and be influenced by the problem and its solution. The artifact distributes stakeholders across different levels that represent different information forces in relation to the problem under analysis (the Operation level) (Baranauskas et al., 2013). The different levels are:

- Contribution (actors, responsible): those who directly contribute to the problem or its solution or are directly affected by it;

- Source (clients, providers): those who provide data and/or are a source of information for the problem or its solution, or make use of it;

- Market (collaborators, competitors): those who support and contribute or those who compete for the same niche;

${ }^{3}$ LeLe Sílabas is available at: https://play.google.com/store/apps/details ?id=com.morgade.lele . Last accessed on September 6, 2020.

GameFono is available at: https://play.google.com/store/apps/details ?id=com.abilio.gamefono . Last accessed on September 6, 2020.

Speech Essentials Therapy App is available at: https://play.google.com/ store/apps/details?id=com.speechessentials.speechessentials . Last accessed on September 6, 2020.

Speech Therapy Flashcards - S is available at: https://play.google.com/ store/apps/details?id $=$ com.speechtx.jennifer.flashcards_s . Last accessed on September 6, 2020 


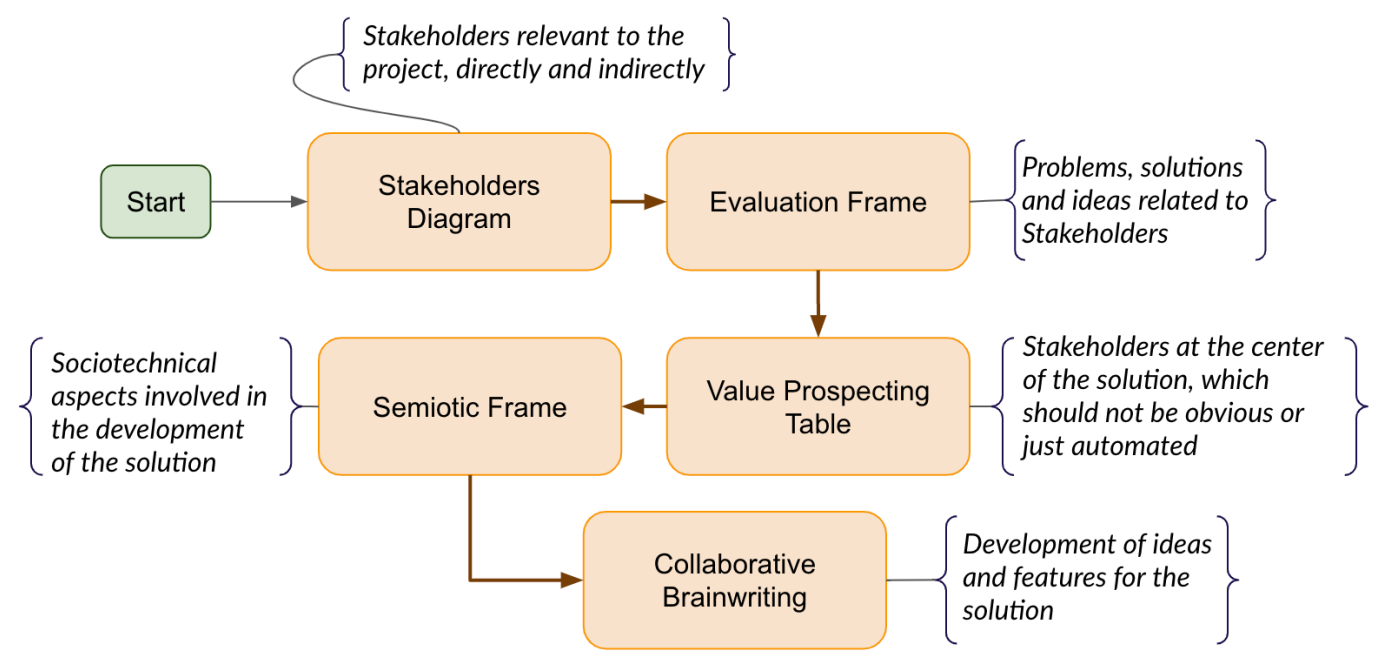

Figure 1. Activities developed in the Socially Aware Design workshop

- Community (bystanders, legislators): representatives who influence and are influenced by the problem in the social context.

Having identified different stakeholders, the Evaluation Frame was used to anticipate the difficulties and ideas each stakeholder would face regarding the problem and its prospective solution (Baranauskas et al., 2013). Taking about 40 minutes, this step was key to promote critical reasoning and empathy towards the different stakeholders and the challenges they face in their life, promoting a sense of responsibility and provoking designers to think ahead of limitations and challenges as well as possible ways of dealing with them.

Based on the shared understanding about stakeholders, challenges and ideas, the Value Prospecting Frame was used to support discussions about who, among the stakeholders identified, is the central stakeholder for the solution the team will design. For these stakeholders (usually one or two), it is mandatory to identify their real needs, difficulties, fears, and challenges, especially identifying how a computational solution could improve their lives, adding to their quality of life in its widest possible sense. The solution must be innovative, going beyond specifying a common solution, and positively surprising stakeholders. The Value Prospecting Frame has five blocks: (1) Central Stakeholder(s), the starting point for filling in the other blocks; (2) What do they (central stakeholders) really need and (3) What difficulties do they face, both blocks related to the problem context focusing on the needs of central stakeholders; (4) How can a solution improve their lives? and (5) How can a solution surprise and innovate?, both blocks for the solution context focusing on its intended value to central stakeholders.

After identifying the central stakeholders, their demands and challenges for both problem and solution, the Semiotic Framework from Stamper (Stamper, 1993, 2001) was used to structure and organize requirements for the solution to be designed, inviting designers to consider from technical infrastructure requirements to environmental and social requirements. This step took about 30 minutes and resulted in requirements related to the Semiotic Framework six layers:
1. Social World: consequence of the uses of signs in human activities; deals with beliefs, expectations, etc.;

2. Pragmatics: studies the intentional use of signs and the behavior of their agents;

3. Semantics: deals with the relationships between a sign and what the sign refers to;

4. Syntactics: deals with the combination of signs without considering their specific meaning;

5. Empirics: deals with the static properties of signs when different media and physical devices are used;

6. Physical World: works with the infrastructure, the physical aspects of signs and their marks.

The upper three Semiotic Framework's layers are related to human information functions in the use of signs, how they work in communicating meanings and intentions, and what are the social consequences of their use. The lower three layers are related to information system technical infrastructure related to how signs are structured and used in language, how they are organized and conveyed, the physical properties they have, etc. (Stamper, 1993).

With participants having a shared understanding of the problem and the requirements for a prospective solution, the Brainwriting technique was used to develop themes for the game and ideas on how it should operate. This step took about 50 minutes, resulting in a collection of written ideas produced by participants collaboratively and democratically (VanGundy, 1984). The main objective was not to define how the game should be or to identify functional requirements, but to prospect ideas for further exploration with the domain stakeholders (health professionals, families etc.).

The Brainwriting technique allows everyone to contribute to the development of a solution democratically and collaboratively. At the end of the workshop, the final object was conceived through the action of all the participants. For our workshop, results were ideas for how the solution should be built, as well as themes for the interaction with the game and its story. More important, however, is the shared understanding designers build during these practices, thinking ahead, socializing opinions and concerns, seeing ideas from each other. 


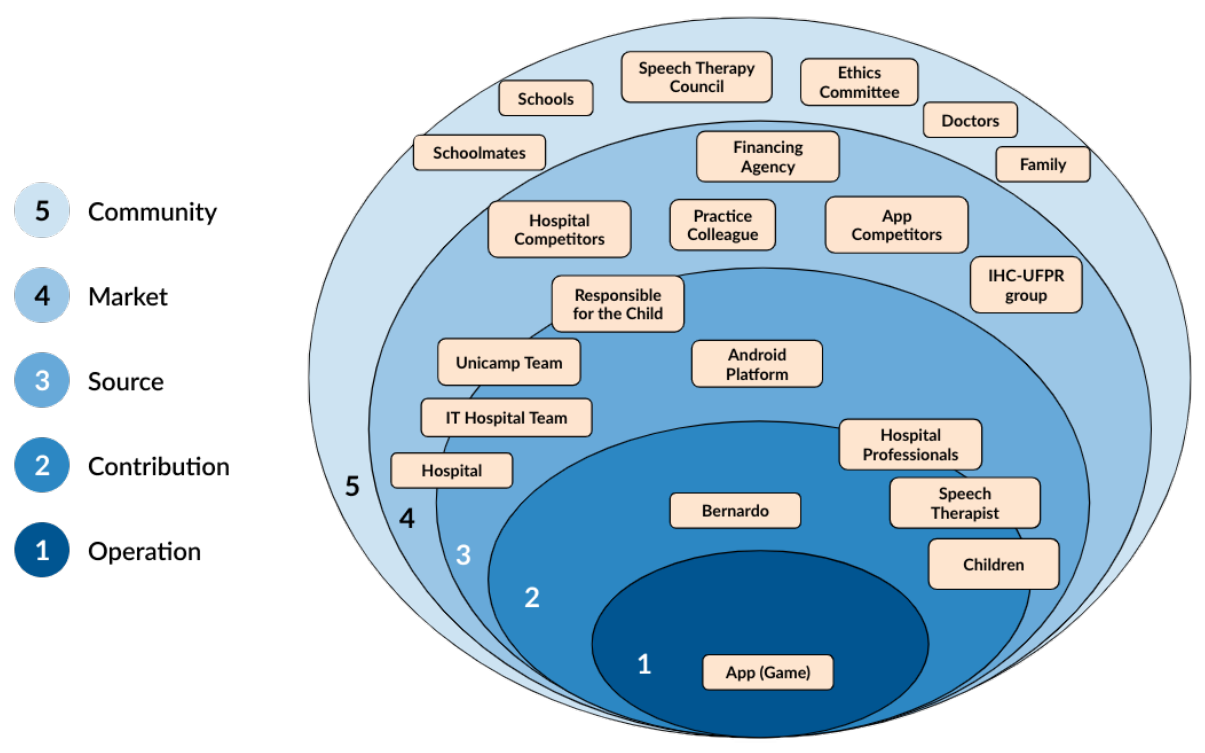

Figure 2. Stakeholders Diagram filled by the workshop participants.

For the activity, there was a socialization moment where participants talked about the resulting ideas and, then, a consolidation moment where results were organized and delivered for the interested designer to use as inspiration for prototyping a prospective game. After the end of the Brainwriting activity, thanks were given, and the workshop was concluded.

\section{Workshop Results}

This section highlights results from our early workshop (the understanding of the problem domain produced from the fulfillment of artifacts) as well as a prospective game prototype based on the produced understanding.

\subsection{Artifacts and Techniques}

In the Stakeholder Identification Diagram, 21 stakeholders who may influence or be influenced by the problem or its solution were identified. Figure 2 presents stakeholders spread on the artifact layers. A stakeholder may belong to more than one layer as it plays different roles for a design context. For example: "Hospital professionals", "Speech therapist" and "Children" belong both to Contribution and Source layers as they may be involved directly in design activities (contribution), and are key clients for the solution and providers of valuable information (source).

The identified stakeholders are diverse, covering different aspects of the problem and its prospective solution. They also go beyond the obvious ones, such as children and the speech therapists, favoring to identify those that although are not direct users for the solution, are crucial to to promote or enable its use. The following stakeholders were identified:

- for implementing the technical solution: Bernardo (first author), IHC-UFPR Research Group, Unicamp partners, IT Hospital team;

- speech therapy: children, speech therapists, hospital professionals, responsible for children, doctors, colleagues of practice;

- in children's daily life: schools, schoolmates, family;

- other stakeholders: speech therapy board, ethics committee, app competitors, funding agency, hospital competitors.

We identified possible partners and competitors for the solution's success, such as existing apps, and stakeholders that regulate possible uses of a solution, such as the speech therapy board and ethics committee. Stakeholders from children's daily life inform us about possible users who can also benefit from a solution or at least influence children to use it. For obvious reasons, stakeholders involved in speech therapy must be consulted or even directly involved in designing or evaluating an intended solution.

When discussing the roles of different stakeholders, we realized that children may eventually carry out speech therapy activities in different settings other than the hospital, such as at their own home, relatives' home, at school and other public spaces. When children are in these settings, other people can be part of the activity and can influence on children's behavior in both positive and negative ways. On the one hand, children may feel shame, fears or anxieties of doing their exercises when other people are seeing - and children may have no space for their own. On the other hand, there are possibilities for creating collaborative experiences that put people together and help children to internalize the playful aspect and the importance of the therapeutic exercises.

For the Evaluation Frame, because our purpose with an early workshop is to create a shared understanding instead of an exhaustive one, we selected not all but a subset of stakeholders considered most important to be discussed and analyzed in terms of challenges and ideas. For selecting stakeholders, we followed the recommendation from the literature (Pereira and Baranauskas, 2015) ensuring that at least one stakeholder from different layers of Stakeholder Identification Diagram had been included in the Evaluation Frame. By selecting stakeholders from each level, we avoid ignoring important information forces that affect the design problem or 
its prospective solution.

The Evaluation Frame incited participants to anticipate challenges and requirements that directly inform us about how a prospective solution should be and operate, as well as about issues we should keep in mind. For example, the importance of aspects related to usability, accessibility and user experience, motivation and interest, personalization, and technical infrastructures (e.g., data synchronization, access to the internet). We verified information related to the problem social context as, for example, families very often do not have access to the internet, which demands a solution not to depend on internet connection to work and not to consume mobile data. As another example, families can be heterogeneous and, although the mother is usually the most present person, the person who accompanies children in their day-to-day activities and with hospital care can vary. Family members and other stakeholders can be allies, beneficiaries or act hindering the adoption and usage of a designed solution.

Bases on discussions around the Evaluation Frame, key assumptions were made:

- families may not have technical resources to use the solution, such as smartphones devices and internet access;

- children may not have a unique and personal device to use the solution;

- it is not just about solving speech therapy exercises, but an activity that involves other aspects, such as:

- use of smartphones or other mobile devices;

- competition with other tasks, apps or games;

- lack of time, support or engagement to carry out activities;

- embarrassment in carrying out activities that involve speaking;

- different accessibility issues.

Supported by the Value Prospecting Frame, several elements were identified for the main stakeholders: Children/Patients and Speech Therapists (see Figure 3). Although all stakeholders are relevant to the problem and its solution, the highest priority must be given for patients because they should want to use the solution and to get the greatest benefit from its use. The importance of speech therapists is because they have the purpose of improving children's speech capabilities and are naturally interested in tools to effectively support their work. Defining central stakeholders is necessary for developing real empathy and understanding. No central stakeholder means a neglected or underlying stakeholder who designers may be ignoring or misunderstanding during the design process. In user-centered projects, it is common for the main user, who is expected to get the main benefit from the solution, to be left out and not be effectively considered as central. In his paper "Reimagining HCI", Bannon (2011) draws attention to different contexts, such as Ambient Assisted Living, in which solutions are developed under motivations for improving the quality of life of people at home instead of staying in hospitals or institutions. However, when examining carefully, it is common solutions to be concerned with providing 24 hours a day monitoring, without explicitly worrying about improving people's quality of life, promoting their autonomy and values. This tends to happen when the main stakeholder is left out of focus since the early stages of problem understanding and solution design.

Supported by the Value Prospecting Frame, we question our understanding and assumptions about the problem domain that may already be set, especially regarding central stakeholders. When questioning what stakeholders actually need, we stressed that children need activities that provide both fun and progress in their treatment and learning. To maintain engagement and use of the solution by children, activities must make sense to them and be interesting, fun, engaging, challenging and easy to learn how to use. Whatever the designed solution would be, practicing exercises must be a natural part of the game.

With a voice-based game, children may be ashamed to play, which can hinder the performance of speaking activities. Besides, families may not encourage or not engage in treatment. Sometimes, only one smartphone may be available for used by all the family members and children may want/need to use it while someone else also needs. Therefore, if on the one hand the availability of a device can be a challenging point depending on the family, on the other hand, it is a problem that can be solved by the hospital and its partners, for example: if a solution can operate on a low-cost device, it could operate on a device offered by the hospital and its donors.

A low-cost and voice-based game solution can contribute to improving children's speech skills, influencing their confidence and developing social skills as well. Such a solution can also assist in engagement and interaction within their families if speech exercise activities also support collaborative interactions.

From a therapeutic perspective, we prospect the solution can surprise and innovate by allowing speech therapy professionals to propose activities tailored for each child and their characteristics, including the social ones. The solution can also innovate by offering resources for analyzing continuing treatment progress, especially regarding the time between consultations in the hospital. The game may be designed to allow children to represent themselves in the game and to create challenges for themselves, as well as for cooperative experiences with other children, growing a sense of mutual help, fun and learning. Recognizing low socioeconomic condition is common between families, storing data on smartphones and transferring them when devices are connected to a Wi-Fi network (e.g., in the hospital) is mandatory, and is something that no other analyzed solution offers. Such a possibility allows healthcare professionals to obtain data on the progress of treatment without burden the patient with data transmission.

Innovation and surprise are relevant elements, for example, to promote engagement with the game, to encourage a feeling of climax, or to attract and keep players' attention. These elements can be the main attractions in a solution and can impact aspects of game implementation and its content.

Different issues for a solution were raised when thinking of it according to the six layers of the Semiotic Framework. The physical layer incited discussions and project definitions such as the Android operating system, which is the operating system present in most smartphones in Brazil population (G1, 2019), especially devices most accessible to the socioeco- 


\section{Central Stakeholder(s) \\ Child / Patient.}

Speech therapist.

\section{What do they really need?}

- Activities that are interesting, make sense, are fun, easy to use, engaging and challenging.

- Activities that provide progress.

\section{What difficulties do they face?}

- Shame to speak.

Lack of family engagement.

Availability and ability to use the device.

\section{How can the solution improve their lives?}

- Improvement of speech skills.

- Better socialization in the family.

- Promotion of the social circle.

\section{How can the solution surprise and innovate?}

- Allowing speech therapists to adapt exercises.

- Allowing children to cooperate among them.

- Allowing children to propose a challenge.

- Data storage should be minimal.

Figure 3. Value Prospecting Frame filled by the participants.

nomically vulnerable population. The solution should operate in smartphones and other mobile devices because i) smartphones allow voice capture more easily by the built-in microphones; ii) in families, smartphones can be more present than computers; and iii) they enable mobility between different contexts, such as home and hospital. Below we present other requirements identified for this layer.

- Supporting data storage and transmission

- Smartphones and Tablets devices

- No mandatory Internet, Wi-Fi

- SMS support

- SMTP (E-mail)

- Supporting voice input data

- App in the style of a game

- Low cost devices

- Android operating system

At the empirics layer, we checked technical aspects like security, encryption, and privacy, which are relevant because the solution may be used to collect information from children. Because families usually do not have broadband internet to transmit data, the solution must not require a high storage capacity as families' smartphones may have limited capacity or already store other information, such as photos, messages, apps, among others. Using cloud services to store audios and other information was considered viable when devices are connected to a Wi-Fi network. Lastly, the solution must be designed for ambient noise to affect the interaction to a minimum. Below we present examples of requirements for this layer.

- Noise from the environment should not disturb children's interaction or audio capture

- Transfer app data to the cloud when Wi-Fi is available

- User can configure how backup works.

- Manage access to app data (photos, videos, audio)

- Data security and privacy, encryption

- Requiring little storage to function

- Storage Capacity: Cloud (Drive-15GB, Dropbox-2GB)

- Free up local space when back-up is successful

On the syntactics layer, we discussed the pros and cons of using Material Design interface pattern. Also, we considered using examples and ideas from ongoing activities at the Hospital, such as the SobraPets theme based on little animals that inhabit the Hospital (Silva et al., 2019). The game designed and its content (visual style, exercises) must be developed under universal design principles, creating activities that are fun and engaging for stakeholders other than children, creating opportunities for activities with their families or colleagues. Game solution must be open source for other hospitals and professional to (re)use it in their practices. Finally, tasks and controls must be intuitive for children to play and for speech therapists to configure, respecting usability and accessibility guidelines. Activities for voice exercise must be clear so users can play appropriate exercises according to their conditions, for example, in silent environments children can have speak activities, or in environments affected by noise children can have listening (and not speaking) activities. Below we present requirements for this layer.

- Priority for universal design and practices, accessible to the greatest possible diversity of population

- Using open source standards

- Open source solution for use in other hospitals by other professionals

- Exercise configuration by speech therapists must not require technical knowledge

- Game must be intuitive especially for children

- Suggesting the right exercise according to players' needs

- Material Design interface pattern

- SobraPets theme for the game

For the semantics layer, the meaning of exercises and features offered to users and those interested in the solution were discussed. Significance of functionalities must be well established to avoid causing embarrassment to users and helping them to achieve their goals, such as achieving the benefits the solution is proposed to offer. Game content must adopt the SobraPets theme, using pets as the setting and characters of the solution, but without creating a design that has too childish characteristics as the game may be played by adults (child's parents) as well. Instead, priority should be given to a pet visual style that can please different audiences, promoting collaborative interaction with other stakeholders. 
Interface elements must be meaningful for children to play autonomously. Children must also be able to share their results, experiences, photos and other information from the solution with other children, creating and sharing collaborative experiences. Below we present requirements for this layer.

- Adopting the SobraPets theme

- Exercise challenges should gradually evolve in difficulty

- Allow sharing with colleagues: results, photos, general status

- Interface elements must be meaningful for children

- Avoid overly childish features and elements

- Guarantee exercises are adequate for children needs

- Inform children and parents about how to perform each exercise

- Features meaning must be clear for players

In the pragmatic layer, aspects the solution is expected to promote were envisioned, such as engagement, visibility, socialization and execution of exercises outside the hospital setting. Adopting the theme already used in other projects at the Hospital, maintaining coherence and promoting engagement with and from other projects was identified as necessary. A feeling of inclusion should be developed through a game theme or story, for example, a villain which would promote the exclusion of other animals in the game and, in the end, the villain should be included ${ }^{4}$. Do not create exercises or activities harmful to players. Speech therapists must be able to tailor activities for each child as they do in individualized treatment. When it comes to engagement, the solution may remind children or their responsible about speech exercises via engaging and funny notifications. During gameplay, a virtual pet (a player can nurture animals through feeding and relationships (Rogers, 2014)) can help and motivate children to complete exercises even in case of failure. Indeed, the notion of "failure" is rather different here, as each child has a particular progress and style, referring to giving up activities instead of not reaching an expected score. If children practice exercises regularly, the solution may also have gamification resources for them and their responsible, for example, congratulating them or offering game rewards: benefits for some action or achievement (Werbach and Hunter, 2012). Finally, the solution can offer a multiplayer mode with collaborative exercises, where players work together to achieve the same objective (Rogers, 2014). The points below summarizes requirements from this layer.

- Exercises created/tailored by therapists

- Provide positive reinforcement (children, responsible) when children perform exercises regularly

- Offering Multiplayer mode for collaborative exercises

- Remind children or responsible through engaging and entertaining

- A virtual pet to support and motivate children when playing notifications

\footnotetext{
${ }^{4}$ Named ExcluVader, the villain fights for exclusion because he is a kangaroo or a T-rex that cannot hug someone and has never experienced hugging. Players' goal is not to defeat the villain but to include him.
}

- Promote speech exercise, evolution in speech treatment, socialization among children, children and family engagement, and promote exercises outside the hospital environment

- SobraPets Theme: maintain consistency as it is already being used in the hospital and can promote engagement

- Engagement and visibility

- ExcluVader: a character who wants to promote exclusion, and players' challenge is to include it

The social world layer was not filled during the workshop but completed by the authors after it as it is based on the discussion from the previous artifacts and the other five layers previously discussed. For this layer, we highlight socioeconomic aspects, such as some families not being able to have a smartphone with advanced technological resources or having only one smartphone at home. We found out that children like themes related to superheroes, in which the solution can use charismatic characters that promote engagement. Aspects of the family and engagement with the treatment were also seen, such as the family forgetting the exercises that children should perform and the family performing other activities with the device, competing for it. Lastly, the importance of the stakeholder Speech Therapy Ethics Committee was also declared, which must approve the exercises, thus not creating negative implications for children. Requirements for this layer are presented below.

- Do not create exercises or features harmful to children

- Offering customization possibilities according to users' social context

- Promote socialization and collaboration via multiplayer and sharing

- Adopt appealing themes for children, such as superheroes

- Raising funding to guarantee an exclusive device for each child

- Follow recommendations and seek authorization from an ethics committee in the speech therapy field

- Offer a communication channel between therapists and family

- Tutorials and help must be available and embedded in the game

Having built a shared understanding of the problem and walked towards a general idea for a game solution, the Brainwriting technique was conducted to generate ideas about the theme of the game. Figure 4 present one of the collective ideas generated.

Common points were found in the written productions and are described below:

- animal theme (inspired by the SobraPets theme already adopted in the hospital)

- create personalized/unique skills for different animals

- allow to select the gender of the game characters

- use specific sounds for specific animals (e.g., "au" or "bark" for dog)

- develop different scenarios and themes (desert, forest, hospital) 


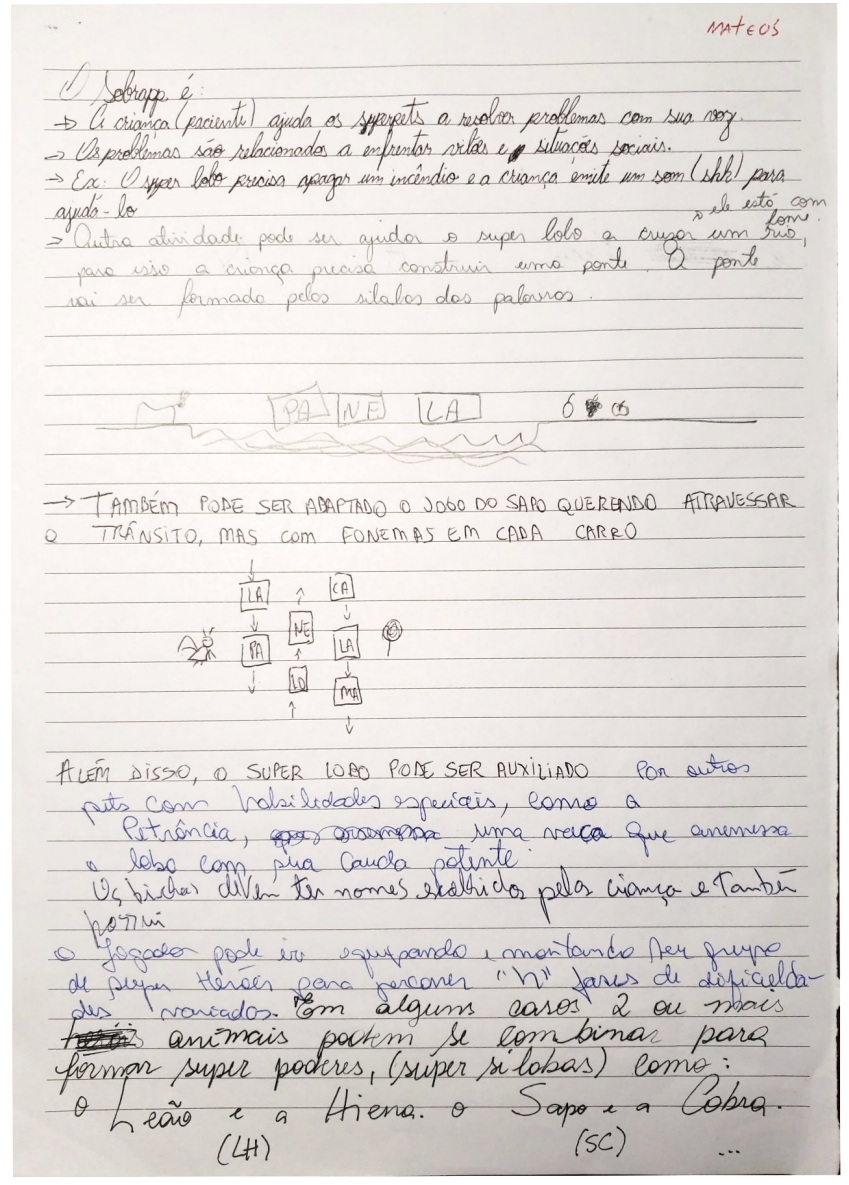

Figure 4. Result from Brainwriting activity for one of the participants. It is possible to see the different ideas from each participant.

- design activities involving a physical environment, for example, words (on paper) hidden in the Hospital building that must be pronounced in the app

- include more challenging levels and enemies (bosses)

- offer several options or modalities of games not to be repetitive for children

- consider representing progress in the game to feed a Pet, make the Pet happy, etc.

- design features to allow children to interact with other children

- offer features for speech therapists to tailor exercises and activities

- offer features for speech therapists to follow users' evolution and performance on exercises and activities

From the writing productions of the participants, ideas inspired by existing games were identified, such as the WarioWare game style with sounds; Flappy Bird with sounds; Soccer (speak words to increase the strength of kicking, kick to the goal); musical games like the Yousician, Piano Tiles and Guitar Hero; Tamagochi (virtual pets) with the SobraPets theme (with gamification); and "Challenge of the day", recording 3 to 5 seconds pronouncing a "super syllable". These ideas have the potential to be used in other similar solutions for speech therapy activities or future versions and expansions of the game as a support platform, representing examples of highly engaging and fun gameplay, and are examples of ideas for games that adjust to the challenge of speech therapy and the children audience. Lastly, the game design should consider the sociotechnical elements seen in the artifacts.

Although several ideas were generated, we highlight that the main purpose of this workshop is not solving the problem but understanding it, raising the participants' sensitivity and empathy, and promoting a shared understanding about the context, the interested parties, their needs and so on. The results from this workshop help designers to have a better notion of their responsibilities and demands previous to the effective contact and work with other stakeholders. As we mentioned, it is not possible to design a game without working with domain experts and it is not desirable to design a solution without working with its prospective audience. However, we, as designers, must have an ethical responsibility regarding how we use the time and resources from others as well as how we involve them. Therefore, the workshop we present in this paper is all about doing a basic effort towards knowing the problem domain and its challenges so that we can have a minimum knowledge (and doubts) to start useful conversations and actions with our partners and interested parties.

\subsection{A Game Prototype}

A game prototype was developed to show how the ideas from workshop could be implemented and how information for the problem domain contributed to the game design. Therefore this first prototype did not intend to have therapeutic validity as its development did not involve health professionals or domain experts. Thus, the game must be understood as a prototype, without the robustness of a complete solution. For a complete game development, relevant requirements such as accessibility and usability must be properly designed and evaluated in further activities with domain experts.

The target audience for the game was fixed as children of 7-11 years of age, as it was the case of previous workshops in the SOBRAPAR. Also, the game would appeal for children of varying ages because the game theme does not have a childish visual style and the challenges are inspired in famous games, such as Super Mario and Flappy Bird.

Based on workshop results, the Fonopets game was proposed and presented in a functional prototype implemented by the first author. The game was designed for the Android platform, adopting a voice-based interaction style where the act of playing occurs by emitting sounds. The main aspects of the proposed game are:

- promoting the positive experience of children with the game by selecting different types of avatars

- allowing adjustment of goals and daily progress by speech therapists, to promote tailored treatment via game playing

- transmitting videos and audios recorded in the exercises asynchronously

- offering four different types of challenges with simple mechanics, but with repeatability and engagement value

On the game landing interface, there is an animal happy when children do their daily exercises and sad when children do not. Changing in animal's feelings expressions seek to promote engagement so that children keep returning to 
the game and making the animal happier. Fonopets presents daily progress (represented by a progress bar) associated with the animal, whose emotion is reflected by the progress, as represented in a low fidelity prototype in Figure 5. Children can also select which animal they like the most, allowing a level of identity between children-animal.

The progress bar on the landing screen also shows how many points an user needs to get per day. This goal can be customized by speech therapists during consultations to adapt to different treatment intensity (e.g., expected practice frequency). Upon completing the daily goal, the game invites children to take a challenge: to film their own mouth movement pronouncing a syllable or a difficult word in a video of three to five seconds. This video will be stored in the smartphone to be transmitted when a Wi-Fi connection is available. Data storage and transmission can be done through a shared resource in the cloud (e.g., Google Drive or a Dropbox directory) so speech therapists can access and check the progress that occurred since the last consultation. There is also a menu to access each game mode, represented by a different animal.

Choosing modalities for the game was based on the premise children need to play the game daily. Therefore, hardly a single solution would not become repetitive, predictable or tiring after some time playing. Four different modalities have been proposed for Fonopets inspired by ideas from WarioWare game, which groups dozens of games with simple mechanics, but keeping the voice-based interaction style and seeking to promote engagement value. Taking inspiration from the theme already developed with the Hospital, each modality has a different animal as a represented character, for example, bird, rabbit, frog, and snake (four boxes represented in the low fidelity prototype in Figure 5).

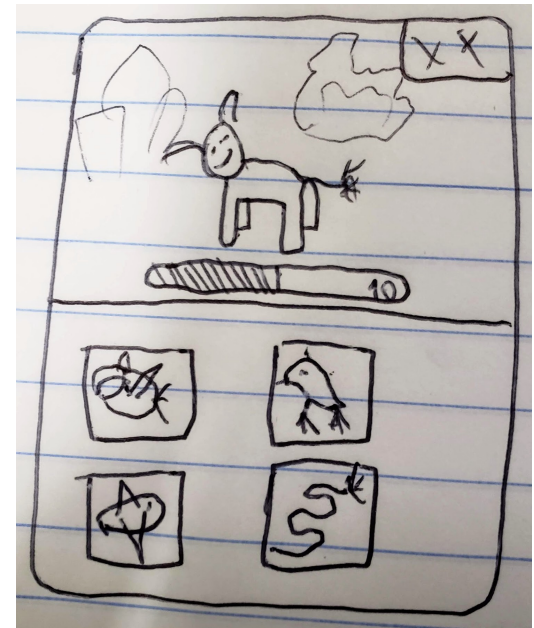

Figure 5. Design of the initial screen of the proposed solution. At the top there is the daily progress (represented by a bar) and an animal, whose emotion is reflected by the daily progress. At the bottom, there is a menu to access each game, represented by a different animal.

The first modality is based on Flappy Bird game: a bird needs to cross several pipes with different heights. Pipes move horizontally with constant speed while a bird moves vertically with the force of gravity. Unlike the original Flappy Bird, game input will be voice-based instead of touchbased. For preventing the game from becoming complex, the force of gravity must be reduced, as well as pipes movement speed.
The second modality is based on Super Mario Bros using voice to control the jump movement of the game character. For the implemented prototype (Figure 6), users are not allowed to control the horizontal movement of the character (which is automatic), but whether gravity will be up or down while the character moves forward. Special blocks were created which, when touched, generate a different situation such as reversing the speed or teleporting the character. For the complete game, mixed mechanics can be used to offer more control forms in which players can control the horizontal movement of the character by touching the screen in addition to the vertical movement by voice.

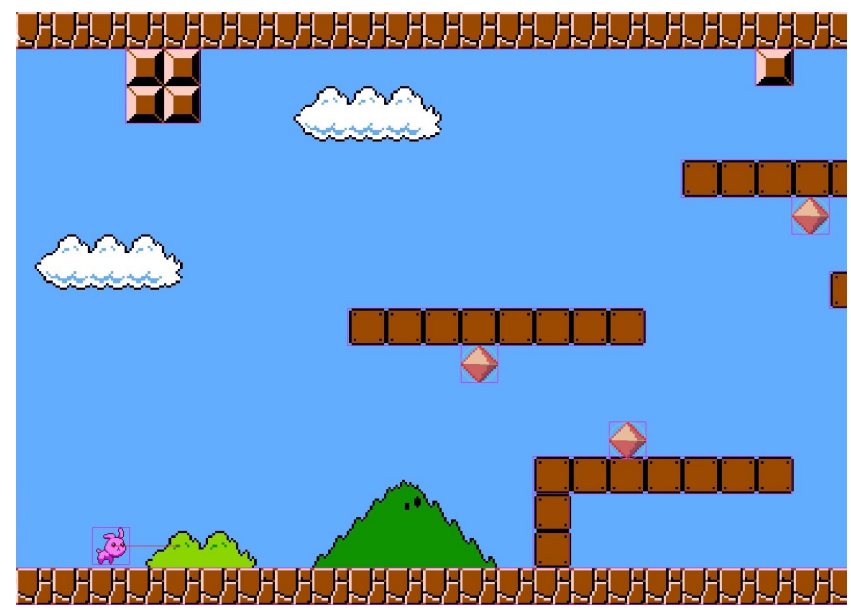

Figure 6. Functional prototype of the second modality.

The third modality is inspired by the game Frogger, in which a frog tries to cross streets and rivers without being hit by traffic or drowning in water. The proposal is that this modality uses voice as a way to move the character forward, in the vertical direction. As some obstacles (e.g., sticks, logs) are in constant horizontal movement, players need to maintain concentration and play precisely. This modality, therefore, depends less on the number of times children pronounces a word and more on its accuracy.

The last and fourth modality is inspired by games such as Guitar Hero, Piano Tiles and Yousician. The goal is for children to say phonemes or words at the right time, following a visual indication on the screen associated with some melody. There may be game modes with several different words and each must be said at the right time. The precision of the speech rhythm can also be explored.

More than children, the game was designed to engage the whole family or close people. As there are inspirations from popular games, these close people can also participate in game challenges. This allows the game to be an object for sharing collaborative experiences and prevents it from being exclusive.

\subsection{Game Implementation}

For the functional prototype, first the game was developed inspired by the Flappy Bird (Nguyen, 2013). A bird moves vertically and pipes move horizontally with an opening between them. The goal is for the bird not to touch the pipes or the ground for as long as possible, with each pipe through 
counting a point for the player score. Even reducing the accelerating force of gravity in the bird or reducing the speed with which the pipes move, preliminary evaluations revealed the game does not work well when voice is used as input since it requires several repetitions in a short time and that any delay in the voice processing can lead to losing the game.

Therefore, the second proposed solution was implemented as a game inspired by Super Mario Bros, in which the character constantly moves horizontally and gravity (vertical force) is reversed at each user voice interaction. The game allows the player to choose pre-defined forms of phonemes to be used as input. Seven levels were developed with each of the first five levels introducing new mechanics through differentiated blocks.

Different mechanics have been implemented for the blocks. The first level (Figure 7-1) introduces common blocks, which can be used as a floor, ceiling or barrier, and the collectible crystals, which are used as a scoring method. The second level (Figure 7-2) introduces green blocks that, when touched, reverse the horizontal direction in which the character is moving. The third level (Figure 7-3) introduces purple blocks that, when touched, teleport the character ten blocks forward. The fourth level (Figure 7-4) introduces gray blocks, which when touched, teleport the character ten blocks back. The fifth level (Figure 7-5) introduces blue blocks, which when touched, make the character jumping. The sixth and seventh level (Figures 7-6 and 7-7) mix all blocks (and mechanics) described above in order to increase the difficulty level. For accessibility matters, other visual information such as single forms can be used as redundancy for indicating different block functions.

The idea behind each new block was to diversify the game and teach the player new strategies. According to Andersen et al. (2012), there are no obvious advantages to using tutorials in games whose mechanics can be discovered experimentally. Therefore, each of the five initial levels starts in a safe environment where the user can touch the new block and find out what happens, where there is no punishment and the player can be rewarded with crystals. Progressing through stages, the player finds a slightly more challenging scenario, and, at the end of the stage, a greater challenge is presented for the player to test his or her abilities on the new mechanics. This gradual increase in difficulty can be seen in Figure 8.

All levels were created with the same size (148 blocks wide and 16 blocks high, where each block is 16 pixels) and have an average duration of approximately one minute. Static images that make up the game visual style were obtained for free from The Spriters Resource website (The Spriters Resource, 2018).

\section{Discussion}

The workshop results were used as input for designing the game as the workshop supported to: i) define what is essential or priority in terms of stakeholders, the main value of the solution and possibilities beyond obvious solutions; ii) clarified that a single game would not be able to favor the resolution of the problem, which implied the idea of different game modules for the same solution; iii) offered a critical percep- tion about the game purpose and its target audience not only in technical terms but also social ones, resulting in a simple game.

The produced game may be understood as a serious game, having a specific context and restricted stakeholders as likely to be favored by the game regarding a therapeutic practice. These stakeholders could not be easily identified in a game for leisure or entertainment, as this type of game has an extensive target audience. For a serious game, which has content that wants to be taught or simulated to a particular individual, stakeholders must be well-known. Socially Aware Design brings a systemic view of the context and the actors who can influence the process of playing, from those who will play the game directly to those who influence the environment and conditions in which playing will be possible or not.

The Evaluation Framework provides a comprehensive view of the different stakeholder's problems. The artifact's potential about the design of a game is to explicitly point out that the game can go beyond being just an educational or entertainment medium, causing or dealing with problems of different orders in an individual's life, from informal and social aspects, to the technical aspects of infrastructure and available resources.

In the Value Prospecting Frame, the element of "how the solution can improve people's lives" is an aspect that may not be explicit in conventional development of games. Explicitly bringing that concern, or reflection at least, is a crucial element for the success of the game and to promote the expected results. Instead of simply using the concept of a game to present speech therapy exercises, these exercises should be intrinsic and natural, happening as an integral part of the game. The Value Prospecting Frame was adapted by the last author to promote participants' social awareness and sensitivity in early design activities. Although the knowledge coming from the Frame could be acquired by other artifacts, like the Business Model Canvas (e.g., fields of "Value Propositions" and "Customer Segments") (Osterwalder and Pigneur, 2010), it is succinct for presenting few points for reflection but comprehensive enough to touch aspects of the stakeholders' "pains" and their challenges, as well as aspects of the solution and their opportunities, being suitable for use in problem-understanding and prospecting ideas workshops.

The Semiotic Framework invited us to think about the possible solution from several perspectives or layers. Any design decision on one layer of the framework triggers modifications to other layers, allowing a systemic view of the solution. The framework can be strengthened in the context of games by combining it with other frameworks especially produced for games, for example, associating the framework layers with the elements of Users, Implementation and Diegetic Universe from E-MUnDi (da Silva Cardoso et al., 2018). This combination could allow verifying the possible solution at different levels of analysis, on the context of the problem, the solution, and elements of a game.

The workshop requires designers to identify stakeholders whether direct or indirect users of the game. In the literature, most stakeholders are limited to possible direct users of games or to the ones very close to their adoption and usage. Undoubtedly, they are relevant for defining motivation and 


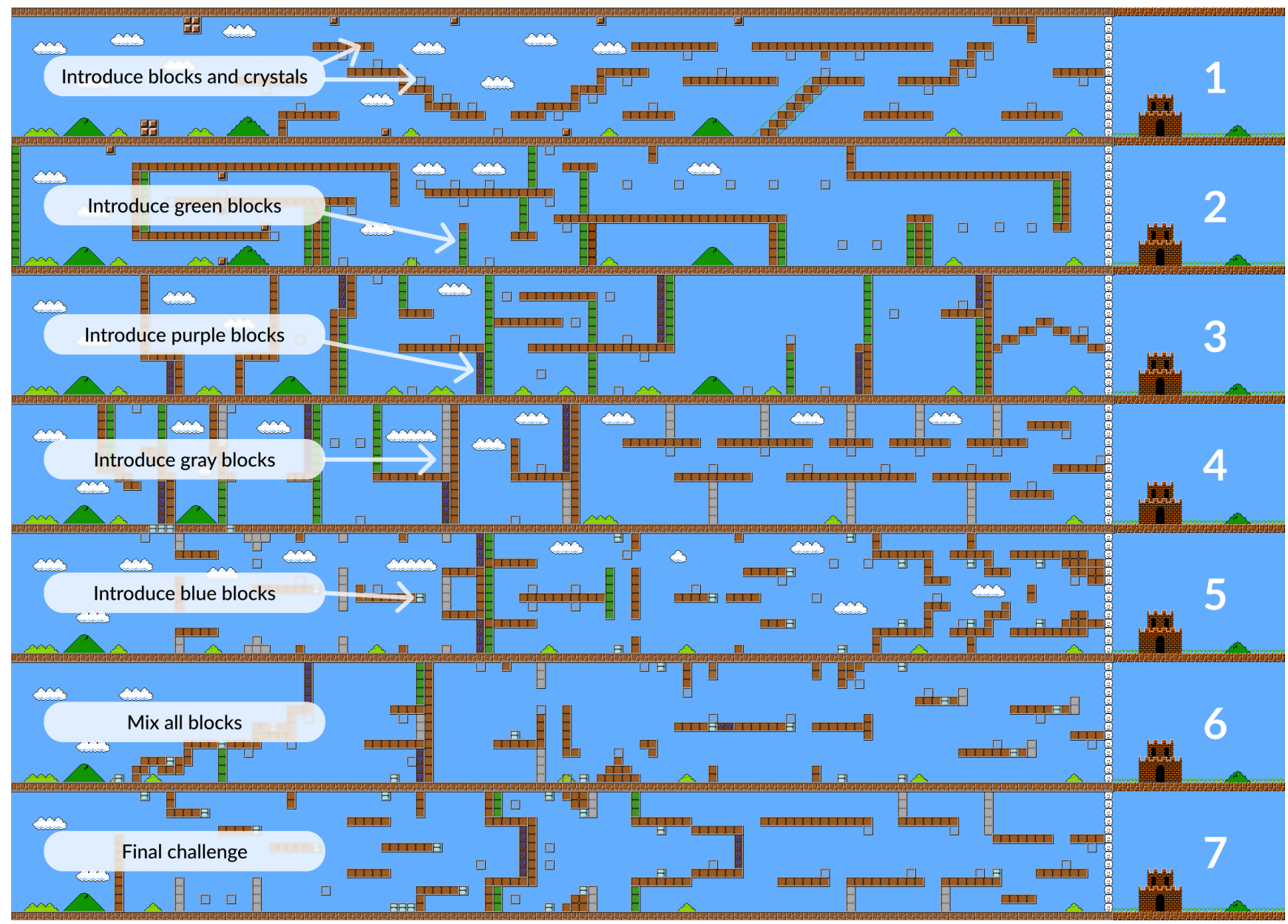

Figure 7. A detailed overview of all levels from the game.

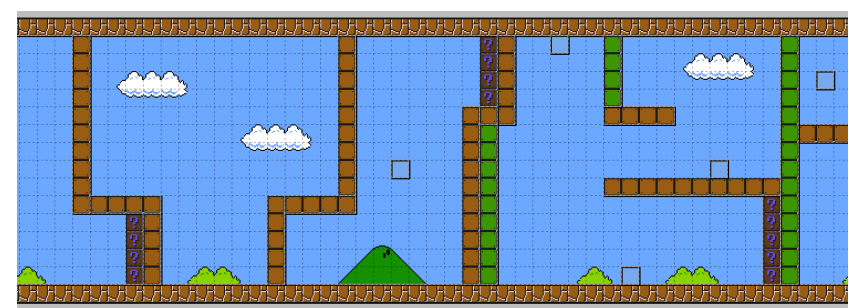

Figure 8. Beginning of level 3 introduces a new mechanic and a gradual increase in difficulty. Transparent blocks are rendered as crystals.

mechanics strategies (Annetta, 2010). However, it is necessary to consider the target audience in a systemic way going beyond obvious users. Participatory and user-centered methods (Vanden Abeele et al., 2012) can support us in this task: while a user-centered method helps us to focus on the needs of the user (Sanders, 2002), participatory design urges us to work directly with prospective users and other important interested parties (Muller, 2002) ) $^{5}$ Our workshop was user centered and inspired by a participatory style, as our purpose was to develop a shared sensibility and responsibility about the problem domain before actually involving other stakeholders.

The artifacts used in the workshop proved to be viable options to support the design of games in understanding the problem and characterizing the solution. Finally, the workshop's approach has the differential of seeking to anticipate

\footnotetext{
${ }^{5}$ Consult Bekker and Long (2000) for a detailed distinction between user-centred design and participatory design.
}

problems and ideas, and to identify for stakeholders the main added value of the game, an element that comes before and can assist in the definition of educational or gameplay strategies.

The workshop lasted 4 hours, but only 2 hours were used for problem-understanding and exploring ideas as a solution, while in the rest of the time participants discussed the artifacts, its fundamental background, and the real context of the problem. During this half-day period (a morning time), we generated several potential ideas for a game that resulted from the practice of identifying stakeholders in scope, verifying the problem and solution at different levels of demands and needs, understand stakeholders and place them at the center of the process, imagining a solution that adds value for them; and generate diverse ideas to be candidates for development, prototyping and testing. This workshop is ideal for the early stages of a game design project, which can be combined with more traditional development modes divided into welldefined stages, or agile modes, with iterative stages focused on rapid production. The main purpose should be to understand the problem from a socially aware perspective before starting working with other stakeholders towards a solution and before involving the prospective audience.

Literature works, such as Neris and Rodrigues (2016) and Mader et al. (2016) highlight the importance of a therapeutic game design that involves different stakeholders of the domain in a participatory approach. We add to this discus- 
sion that an earlier step is necessary: before engaging critical stakeholders, designers need to develop their understanding and sensitivity to the problem. This is a matter of responsibility with the stakeholders and with promoting a shared understanding of the problem, the purpose of the work and the importance of other stakeholders involvement. After conducting this early workshop, the participation of professionals, experts and other relevant stakeholders (e.g., family) in the development process could be focused on what is really essential to known and do. Therefore, if a design team "homework" is done before, the people's scarce time can be treated with responsibility.

The workshop approach, while producing a comprehensive understanding and generating various possibilities for game solution ideas, also has limitations and points of exploration. The approach has a complex understanding and use of concepts. For our practice, those involved received prior training to fill the artifacts and the Ph.D. with knowledge about HCI and Organizational Semiotics acted as a mediator at certain times, explaining concepts, for example. In a real game-building scenario, there is a need for learning before using the artifacts, or mediation by an expert on the concepts used. However, the artifacts that present more complex concepts are, mainly, the Stakeholder Identification Diagram and the Semiotic Framework. The other artifacts have an intuitive filling as they work with aspects closer to designers. If, on the one hand, every process, method or technique requires some level of learning and familiarization, on the other hand, it is natural to expect that an approach that intends to support design in a socially aware and technical perspective will take participants out of their comfort zone and present some level of difficulty.

\section{Related Works}

Literature has related works when it comes to contribution to therapeutic games development, such as Ushaw et al. (2015) and Pirovano et al. (2016), and regarding a sociotechnical motivation and the use of Organizational Semiotic in game development, such as de Souza et al. (2019, 2018). Although an extensive literature review of sociotechnical game development and therapeutic games is beyond the scope of this paper ${ }^{6}$, we present some related works below ${ }^{7}$.

de Souza et al. $(2018,2019)$ present SemTh, a comprehensive participatory approach to therapeutic game design. The approach has four stages from the beginning to the end of a therapeutic game design cycle: (1) Design Problem Clarification, (2) Interaction Modeling, (3) Design Materialization and (4) Evaluation. This approach was inspired by an instance of the semio-participatory design model for the domain of therapeutic information systems (Neris and Rodrigues, 2016). The instance points to artifacts and objectives to be used at different levels of the Semiotic Onion in the design of the therapeutic system. This approach went through an iterative nature of construction, based on research

${ }^{6}$ For a literature review of therapeutic games design, check De Souza (2018); de Souza et al. (2019).

${ }^{7}$ We express our gratitude to the anonymous reviewers who provided a rich reference body and suggested relevant work to develop this section. in different contexts, such as using Interaction Modeling Language to model solutions for elderly patients with depression and students with multiple disabilities (Garcia et al., 2016), and experimenting with a Personas Enrichment Process in a therapeutic context of chemical dependency and depression (Rodrigues et al., 2014, 2015), as well as the context of children undergoing cancer treatment (Rodrigues et al., 2018).

The SemTh approach is similar to our workshop proposal in defending a socially aware (and sociotechnical) vision for the design of therapeutic games, using a framework (and artifacts) from Organizational Semiotics. However, our approach focus on an earlier stage where the design team would be getting prepared for a design project. Therefore, our workshop can be combined with the SemTh approach, serving as a "warm-up session" for the design team before putting SemTh into practice.

In particular, Rodrigues et al. (2018) present a lesson learned from "conducting a brainstorming", which relates to our approach: it reveals the need for a moment of knowledge and empathy building, and creating a common ground between the design team that will develop a solution for a context very sensitive as is the case of therapeutic needs. Rodrigues et al. (2018) mention: "Before the first meeting at the hospital, we did a brainstorming session with the Computer team to discuss what we would need to understand about the scenario and how our strategy would be at that moment. A presentation and a list of issues were then drew up for the meeting". Our approach could be used for brainstorming, favouring a comprehensive understanding of who are the stakeholders of the domain, what are their problems and ideas for solutions, who are the main stakeholders, what do they need and how does the solution could innovate, general requirements for a prospective solution at different connected levels, and a collaborative ideation to prospect ideas which can serve as artifacts to start conversation with domain experts.

Pirovano et al. (2016) propose a methodology for the development of exergames through the definition of therapeutic objectives. The methodology has four steps: 1) definition of primary therapeutic goals (what an user should do) and secondary goals (how user actions should be carried out); 2) transforming goals into simple mechanics of a virtual exercise; 3) transform a virtual exercise into an enjoyable exergame; and 4) handle secondary objectives through monitoring and immediate feedback. The methodology is related to our paper by proposing a contribution to the same context: design of therapeutic games. However, unlike our approach, the methodology does not have a sociotechnical concern, it does not have steps or activities for the purpose of understanding stakeholders, nor does it use instruments or artifacts to enable an understanding of the context of the solution. While our approach is intended to support the initial stages of problem understanding and prospecting for solutions, the methodology by Pirovano et al. (2016) has the purpose of indicating steps and objectives for the entire process of designing a therapeutic game, from the definition of therapeutic objectives to the evaluation of the implemented game. The methodology by Pirovano et al. (2016) and our approach can be complementary.

Ushaw et al. (2015) presents recommendations for incor- 
Table 1. Comparison of stages, research foundation and motivation of related papers

\begin{tabular}{|l|l|l|l|}
\hline Paper & Early Stages & Research Foundation & Research Motivation \\
\hline Our paper & Yes & Organizational Semiotics & $\begin{array}{l}\text { Promote designers' responsibility and problem understand- } \\
\text { ing capacity since the early stages of game design, before } \\
\text { directly engaging other stakeholders. }\end{array}$ \\
\hline $\begin{array}{l}\text { de Souza et al. (2018, } \\
\text { 2019) }\end{array}$ & Yes & $\begin{array}{l}\text { Organizational Semiotics and Par- } \\
\text { ticipatory Design }\end{array}$ & $\begin{array}{l}\text { Present a multidisciplinary and participatory approach to } \\
\text { develop therapeutic games. }\end{array}$ \\
\hline $\begin{array}{l}\text { Maike et al. (2015) } \\
\text { Maike et al. (2018) }\end{array}$ & No & Organizational Semiotics & $\begin{array}{l}\text { Explore NUI devices within the Accessibility context } \\
\text { through Organizational Semiotics lens to design NUI- } \\
\text { based devices. }\end{array}$ \\
\hline Pirovano et al. (2016) & No & $\begin{array}{l}\text { Universal Design, and concepts of } \\
\text { differences and perception. }\end{array}$ & $\begin{array}{l}\text { Propose a design strategy for accessible NUI. } \\
\text { Exergames literature }\end{array}$ \\
\hline Ushaw et al. (2015) & Not mentioned & Authors' own experience & $\begin{array}{l}\text { Transfer experience from making general games in the in- } \\
\text { velop it. }\end{array}$ \\
\hline
\end{tabular}

porating practices and principles of commercial game development into serious gaming for health. Recommendations are divided into Design Practices, Implementation Practices and Data Capture and Analysis. The recommendations serve as principles or premises to be considered in the entire game design process, indicating for example what attributes the game should have (e.g., encouraging, positive and rewarding feedback). Ushaw et al. (2015) is related to our paper as both present contributions to the development of therapeutic games. Our approach is intended to indicate artifacts to understand the problem domain before a design team goes into the field and involves professionals. Our approach is not intended to define game design elements, such as principles, restrictions, or attributes of a game. In the development process that begins after our approach, the recommendations by Ushaw et al. (2015) can be considered as premises for the design and implementation of a game project as they represent generic characteristics to be considered in a therapeutic context game.

Maike et al. (2015) presents an investigation with the artifacts of Organizational Semiotics (Stakeholder Identification Diagram, Evaluation Frame and Semiotic Framework) to develop Natural User Interfaces (NUI) solutions that facilitate daily actions for users with disabilities, in the perspective of Universal Design. The relationship is that our approach also uses artifacts from Organizational Semiotics to understand a problem and the Semiotic Framework to explore solution ideas. However, the approach of Maike et al. (2015) is focused on Natural User Interaction devices and the possibilities they offer to obtain an accessible solution from a universal or assistive perspective. Although Maike et al. (2015) does not deal with games or therapeutic aspects, their work can be useful to support further stages of game design after our workshop.

Maike et al. (2018) present a literature analysis and a case study for proposing a design strategy from the perspective of the concepts of difference and perception. The literature analysis revealed four different strategies and purposes in proposing solutions that contemplate the concepts of NUI, accessibility and games. The case study evaluated a memory game adapted to address accessibility issues. The game was eval- uated with four blind people through the Self-Assessment Manikin and a debriefing session to collect collective qualitative feedback. The authors concluded that the strategy for designing a game that provides both accessibility and natural interaction should strive to find a balance between accommodating differences between users, and providing multiple channels for the perception of information. As the paper focus was on the game evaluation, the process of the memory game development was not presented. Therefore, we can not compare if Maike et al. (2018) design methodology was similar to our approach. For our workshop, Maike et al. (2018) report interesting considerations for the universal design of a therapeutic game, such as not focusing on specific differences, but incorporating them into the design, and strive for sensory redundancy instead of sensory substitution, which can be useful to raise designers awareness of issues related to accessibility, inclusion and differences.

We summarize this related works discussion in Table 1, comparing the design stages of each contribution, its methodological base and motivation. By early stages we mean the very first activities even before problem definition where the design team understand and characterize a problem domain. By all stages we mean at least a cycle of design, development and evaluation. In the Table 1, we can see that our paper is destined to the early stages of a design process. Also, we can see that our paper have the same methodological base of de Souza et al. $(2018,2019)$ and Maike et al. $(2015,2018)$ papers but with different work motivations, therefore, suggesting possibilities for extensions and future works.

\section{Lessons Learned}

From the experience reported in this paper, some lessons were learned and can be presented to inform socially aware design workshops:

1. Sociotechnical analysis from the artifacts filling was not laborious to do. The entire process took place over 4 hours and was essential to the game built. This contradicts the idea that it is better to start a project by implementing or prototyping a solution instead of analyzing it. We endorse the importance of agile methods and their core principles, but we claim 
that when the problem domain is critical, regardless the process adopted, a warm-up workshop informed by a socially aware design must be the starting point.

2. The workshop prevented participants from focusing only on the obvious stakeholders. For example: it is important to think about how the family can participate or be affected by the solution, rather than just the child.

3. The presence of a specialist in the theoretical concepts of artifacts was positive. In other workshops, it is recommended that a specialist be present, or that a member of the project assume this specialist position, studying concepts and artifacts before the workshop takes place.

4. The presence of a mediator who filled in the artifacts during the discussion was positive. Participants preferred to discuss the issues that arose than write on the post-its. The mediator captures the discussion and represents in the artifacts, for example by writing on post-its.

5. Half of the workshop time was spent in the introduction, explaining about the problem at the partner hospital and the artifacts to be used. For contexts where more time is available or where there is no need for such a detailed explanation about artifacts, a Braindrawing can be applied to generate proposals for the game prototype.

6. Right after the end of the workshop, it is positive to pass the information of the artifacts to the digital medium. In the workshop, stick-notes were posted on a physical banner, and some could disappear if the banner was transported elsewhere. The information may also need to be detailed, and if when it is retrieved after a long time, it may not be possible to remember what the information is about.

7. The Value Prospecting Frame was the artifact that most helped us to visualize how the solution to be proposed could be relevant, innovative and that truly improves the lives of stakeholders. This artifact is central to the workshop process, linking artifacts from the problem domain (Stakeholder Identification Diagram and Evaluation Frame) to the artifacts to think about the solution domain (Semiotic Framework and Brainwriting).

\section{Conclusion}

This paper presented a Socially Aware Design workshop held to understand the problem from a sociotechnical perspective and to prospect ideas in the early stages of design processes. The workshop was characterized by different practices mediated by artifacts and exemplified in a practical case study when participants were designing a digital game to support speech therapy exercises activities. The workshop produced a collaborative understanding of the problem domain and the impacts of the solution, such as the needs of stakeholders and the existing opportunities in the domain.

In the development of traditional games, the social and responsible concern of a game may not be explicit, especially the negative impacts that it can cause. The socially aware workshop promoted a broader discussion on the positive impacts that should be explored and negative aspects that should be considered. More important: such a discussion must happen in the very start of a game design project.
The workshop, in addition to identifying the obvious stakeholders of the solution, helped to identify indirect users; the Value Prospecting Frame favored an understanding more related to empathy, investigating for the central stakeholder what could be the main value of the solution. The Semiotic Framework helped us to consider sociotechnical aspects, from the technical part to the human issues. The collaborative Brainwriting, in turn, produced requirements and ideas in the greatest possible diversity, offering not only functionalities, but non-functional requirements related to the game quality attributes and restrictions for its adoption and usage.

Results of the workshop were used as input for designing a game prototype for the Android platform. The game is already operable and has been evaluated by different users, which found evidence of engagement between user-game. Since the workshop favors a socially aware understanding, we tend to avoid obvious solutions and approaches that consider "users" as subject to technology, recognizing stakeholders as interested parties where the central one must get effective benefit from the designed solution.

For future research, new empirical investigations can reveal strong and weak aspects of the workshops through new applications with different techniques, participants and problems. The empirical knowledge may enable us to advance in both workshops' theoretical and methodological grounds.

\section{Acknowledgements}

We appreciate the valuable contributions and participation of the members of the IHC-UFPR laboratory. This paper is partially supported by the Coordination for the Improvement of Higher Education Personnel - Brazil (CAPES) - Financing Code 001. This paper is a translated, extended and revised version of a paper entitled (in Portuguese) "Design Socialmente Consciente de Jogos: relato de uma oficina prática para o entendimento do problema e prospecção de ideias" published at the First Workshop on Interaction and User Research in Game Development. The authors thank the Editors for the invitation and the anonymous reviewers for their contribution.

\section{References}

Andersen, E., O’Rourke, E., Liu, Y.-E., Snider, R., Lowdermilk, J., Truong, D., Cooper, S., and Popovic, Z. (2012). The impact of tutorials on games of varying complexity. In Proceedings of the SIGCHI Conference on Human Factors in Computing Systems, CHI '12, page 59-68, New York, NY, USA. Association for Computing Machinery.

Annetta, L. A. (2010). The "i's" have it: A framework for serious educational game design. Review of General Psychology, 14(2):105-113.

Bannon, L. (2011). Reimagining hci: Toward a more humancentered perspective. Interactions, 18(4):50-57.

Baranauskas, M. C. C. (2009). Socially aware computing. In Proceedings of International Conference on Engineering and Computer Education, volume 6, pages 84-88. Claudio da Rocha Brito \& Melany M. Ciampi.

Baranauskas, M. C. C. (2015). Sistemas sócio-enativos: investigando novas dimensões no design da interação 
mediada por tecnologias de informação e comunicação. FAPESP Thematic Project (2015/165280).

Baranauskas, M. C. C., Martins, M. C., and Valente, J. A. (2013). Codesign de Redes Digitais: tecnologia e educação a serviço da inclusão social. Penso Editora.

Bekker, M. and Long, J. (2000). User involvement in the design of human - computer interactions: Some similarities and differences between design approaches. In McDonald, S., Waern, Y., and Cockton, G., editors, People and Computers XIV - Usability or Else!, pages 135-147. Springer London, London.

da Silva Cardoso, J. V., Schmidt, E. L., and Pereira, R. (2018). E-mundi - um framework conceitual para a análise e concepção de jogos eletrônicos. In Anais do $27^{\circ}$ Simpósio Brasileiro de Jogos e Entretenimento Digital, pages 142-151.

De Souza, P. M. (2018). Abordagem para o Design de Jogos Digitais Terapêuticos. $115 p$. PhD thesis, Dissertação de mestrado. Universidade Federal de São Carlos. São Carlos, SP.

de Souza, P. M., da Hora Rodrigues, K. R., Garcia, F. E., and de Almeida Neris, V. P. (2018). Towards a semiotic-based approach to the design of therapeutic digital games. In Liu, K., Nakata, K., Li, W., and Baranauskas, C., editors, Digitalisation, Innovation, and Transformation, pages 5362, Cham. Springer International Publishing.

de Souza, P. M., Rodrigues, K. R. d. H., and de Almeida Neris, V. P. (2019). Semth: An approach to the design of therapeutic digital games. In Proceedings of the 18th Brazilian Symposium on Human Factors in Computing Systems, IHC '19, New York, NY, USA. Association for Computing Machinery.

Ferrari, B., Junior, D. S., Oliveira, C., Ortiz, J., and Pereira, R. (2019). Design socialmente consciente de jogos: relato de uma oficina prática para o entendimento do problema e prospecção de ideias. In Anais do I Workshop sobre Interação e Pesquisa de Usuários no Desenvolvimento de Jogos, pages 11-20, Porto Alegre, RS, Brasil. SBC.

Frost, S. and McCrindle, R. J. (2016). Speech development and therapy using the kinect. International Journal of Child Health and Human Development, 9(3):269-279.

G1 (2019). Em 10 anos no brasil, android foi de 2 smartphones para sistema operacional dominante do mercado. Acessible in https://g1.globo.com/economia/ tecnologia/noticia/2019/11/26/ha-10-anosno-brasil-android-foi-de-2-smartphonespara-sistema-operacional-dominante-domercado.ghtml Online; accessed 31-March-2020.

Garcia, F. E., da Hora Rodrigues, K. R., and de Almeida Neris, V. P. (2016). An interaction modeling language for therapeutic applications. In Proceedings of the 15th Brazilian Symposium on Human Factors in Computing Systems, IHC '16, New York, NY, USA. Association for Computing Machinery.

Krischke, S., Weigelt, S., Hoppe, U., Köllner, V., Klotz, M., Eysholdt, U., and Rosanowski, F. (2005). Quality of life in dysphonic patients. Journal of Voice, 19(1):132-137.

Kummer, A. W. (2013). Cleft palate \& craniofacial anomalies: Effects on speech and resonance. Nelson Education.
Leitão, C., Maciel, C., Piccolo, L. S. G., Salgado, L., de Souza, P. C., Prates, R., Pereira, R., and Pereira, V. C. (2017). Human values in hci: A challenge for the grandihcbr. In Proceedings of the XVI Brazilian Symposium on Human Factors in Computing Systems, IHC 2017, New York, NY, USA. Association for Computing Machinery.

Lenhart, A., Kahne, J., Middaugh, E., Macgill, A. R., Evans, C., and Vitak, J. (2008). Teens, video games, and civics: Teens' gaming experiences are diverse and include significant social interaction and civic engagement. Pew internet \& American life project.

Mader, S., Levieux, G., and Natkin, S. (2016). A game design method for therapeutic games. In 2016 8th International Conference on Games and Virtual Worlds for Serious Applications (VS-GAMES), pages 1-8. IEEE.

Maike, V. R., Posada, J. E. G., and Baranauskas, M. C. C. (2018). A memory game for all: Differences and perception as a design strategy. In 17th Brazilian Symposium on Games and Digital Entertainment (SBGames 2018).

Maike, V. R. M. L., Buchdid, S. B., and Baranauskas, M. C. C. (2015). Designing natural user interfaces scenarios for all and for some: An analysis informed by organizational semiotics artifacts. In Liu, K., Nakata, K., Li, W., and Galarreta, D., editors, Information and Knowledge Management in Complex Systems, pages 92-101, Cham. Springer International Publishing.

Michael, D. R. and Chen, S. L. (2005). Serious games: Games that educate, train, and inform. Muska \& Lipman/Premier-Trade.

Muller, M. J. (2002). Participatory Design: The Third Space in HCI, page 1051-1068. L. Erlbaum Associates Inc., USA.

Neris, V. P. d. A. and Rodrigues, K. R. H. (2016). Design of therapeutic information systems as indicating through signs. In Baranauskas, M. C. C., Liu, K., Sun, L., Neris, V. P. d. A., Bonacin, R., and Nakata, K., editors, Socially Aware Organisations and Technologies. Impact and Challenges, pages 203-208, Cham. Springer International Publishing.

Nguyen, D. (2013). Flappy bird. Apple App Store.

Novak, J. (2011). Game development essentials: an introduction. Cengage Learning, New York, NY, USA.

Osterwalder, A. and Pigneur, Y. (2010). Business model generation: a handbook for visionaries, game changers, and challengers. John Wiley \& Sons.

Pereira, R., Baranauskas, M. C., and Liu, K. (2018). An essay on human values in hci. Journal on Interactive Systems, 9(1).

Pereira, R. and Baranauskas, M. C. C. (2015). A valueoriented and culturally informed approach to the design of interactive systems. International Journal of HumanComputer Studies, 80:66-82.

Piccolo, L. S. G. and Pereira, R. (2017). Culture-based artefacts to inform ict design: foundations and practice. $A I \&$ SOCIETY, 34(3):437-453.

Pirovano, M., Surer, E., Mainetti, R., Lanzi, P. L., and Alberto Borghese, N. (2016). Exergaming and rehabilitation: A methodology for the design of effective and safe therapeutic exergames. Entertainment Computing, 14:55 - 65 . 
Pollonio, C. F. and Freire, R. M. d. C. (2008). O brincar na clínica fonoaudiológica. Distúrbios da Comunicação, 20(2):267-278.

Rodrigues, K., Garcia, F., Bocanegra, L., Gonçalves, V., Carvalho, V., and Neris, V. (2015). Personas-driven design for mental health therapeutic applications. Journal on Interactive Systems, 6(1).

Rodrigues, K. R. H., Bocanegra, L. F., Gonçalves, V. P., Carvalho, V. G., and Neris, V. P. A. (2014). Enriquecimento de personas para apoio ao design de aplicações terapêuticas para a saúde mental. In Proceedings of the 13th Brazilian Symposium on Human Factors in Computing Systems, IHC '14, page 51-60, BRA. Sociedade Brasileira de Computação, Sociedade Brasileira de Computação.

Rodrigues, K. R. H., Conrado, D. B. F., and Neris, V. P. A. (2018). Lessons learned in designing a digital therapeutic game to support the treatment and well-being of children with cancer. In Marcus, A. and Wang, W., editors, Design, User Experience, and Usability: Users, Contexts and Case Studies, pages 231-243, Cham. Springer International Publishing.

Rogers, S. (2014). Level Up! The guide to great video game design. John Wiley \& Sons.

Sanders, E. B.-N. (2002). From user-centered to participatory design approaches. In Design and the social sciences, pages 18-25. CRC Press.

Santos, A. C. d., Muriana, L. a. M., Pimenta, J. R. O. G., Silva, J. V. d., Moreira, E. A., and Reis, J. C. d. (2019). Investigating aspects of affectibility for universal access in socioenactive system scenarios. In Proceedings of the 18th Brazilian Symposium on Human Factors in Computing Systems, IHC '19, New York, NY, USA. Association for Computing Machinery.

Schipor, O. A., Pentiuc, S. G., and Schipor, M. D. (2012). Improving computer based speech therapy using a fuzzy expert system. Computing and Informatics, 29(2):303-318.

Schuler, D. and Namioka, A. (1993). Participatory Design: Principles and Practices. L. Erlbaum Associates Inc., USA.

Silva, J. V. D., Maike, V. R. M. L., Muriana, L. M., Brennand, C. V. L. T., Pereira, R., Lima, T., and Baranauskas, M. C. C. (2019). Explorando afeto e sócioenação no cenário de um hospital. Technical report, Universidade Estadual de Campinas, Instituto de Computação.

Stamper, R. (1993). A semiotic theory of information and information systems. In Randell, B., editor, Proceedings of the Joint ICL/University of Newcastle Seminar on the Teaching of Computer Science, Part IX: Information, pages 1-33, Australia. University of Newcastle.

Stamper, R. K. (2001). Organisational semiotics: Informatics without the computer? In Information, organisation and technology, pages 115-171. Springer.

Stamper, R. K., Liu, K., Hafkamp, M., and Ades, Y. (2000). Understanding the roles of signs and norms in organizations - a semiotic approach to information systems design. Behaviour \& information technology, 19(1):15-27.

The Spriters Resource (2018). The Spriters Resource - Super Mario Bros. https://www.spriters-resource.com/ nes/supermariobros/sheet/52571. Online; accessed in November 2018.

Ushaw, G., Davison, R., Eyre, J., and Morgan, G. (2015). Adopting best practices from the games industry in development of serious games for health. In Proceedings of the 5th International Conference on Digital Health 2015, DH '15, page 1-8, New York, NY, USA. Association for Computing Machinery.

Vanden Abeele, V., De Schutter, B., Geurts, L., Desmet, S., Wauters, J., Husson, J., Van den Audenaeren, L., Van Broeckhoven, F., Annema, J.-H., and Geerts, D. (2012). P-iii: A player-centered, iterative, interdisciplinary and integrated framework for serious game design and development. In De Wannemacker, S., Vandercruysse, S., and Clarebout, G., editors, Serious Games: The Challenge, pages 82-86, Berlin, Heidelberg. Springer Berlin Heidelberg.

VanGundy, A. B. (1984). Brain writing for new product ideas: an alternative to brainstorming. Journal of Consumer Marketing, 1(2):67-74.

Werbach, K. and Hunter, D. (2012). For the win: How game thinking can revolutionize your business. Wharton Digital Press.

Westera, W., Nadolski, R., Hummel, H. G., and Wopereis, I. G. (2008). Serious games for higher education: a framework for reducing design complexity. Journal of Computer Assisted Learning, 24(5):420-432.

Yusoff, A., Crowder, R., Gilbert, L., and Wills, G. (2009). A conceptual framework for serious games. In 2009 Ninth IEEE International Conference on Advanced Learning Technologies, pages 21-23. IEEE. 